\title{
História em quadrinhos no Brasil: traduzindo a História
}

Thaïs Flores Nogueira Diniz, Faculdade de Letras, Universidade Federal de Minas Gerais, Belo Horizonte, MG); E-mail: $<$ tfndiniz@gmail.com>.

Camila Augusta Pires de Figueiredo, Faculdade de Letras, Universidade Federal de Minas Gerais, Belo Horizonte, MG); E-mail: $<$ camilafig1@gmail.com>.

\section{Resumo}

Os fatos históricos sempre mereceram a atenção de artistas que projetaram sua visão em pinturas e outros tipos de ilustração, obras que funcionam como traduções intersemióticas e também como documentos históricos. Não foi diferente com a história do Brasil quando artistas, principalmente estrangeiros, pintaram quadros memoráveis, descrevendo fatos importantes da nossa História. Como forma de atualizá-las e trazer às crianças brasileiras 0 interesse pelas obras de arte do passado, 0 artista brasileiro Mauricio de Sousa apropriou-se de algumas delas e as exibiu na exposição intitulada História em quadrões, que celebrou os 50 anos de sua carreira. $O$ presente trabalho visa analisar criticamente as relações intermidiáticas entre duas telas do passado - $A$ dança dos Tapuias, de Albert Eckhout, e $O$ lavrador de café, de Cândido Portinari - e suas apropriações pelo quadrinista brasileiro.

Palavras-chave: tradução intersemiótica, história em quadrinhos, Turma da Mônica, Mauricio de Sousa, Albert Eckhout, Cândido Portinari.

Os quadrinhos modernos surgiram na década de 1830, com o artista Rodolphe Töpffer. Apesar de serem mais antigos que o cinema, ainda encontram resistência em seu reconhecimento como arte e como objeto de estudo em universidades e centros de pesquisa. Felizmente, essa situação tem mudado, mas, mesmo assim, os quadrinhos ainda lutam pelo reconhecimento cultural e acadêmico. Talvez por isso, em vários países, recebeu nomes diferentes. Em inglês, comics; para os franceses, bande dessinée (ou simplesmente $B D$ ); para os italianos, fumetti; os espanhóis chamam de tebeo; os hispanoamericanos, historietas; e para os portugueses, banda 
desenhada. No Brasil, é chamado de histórias em quadrinhos, mas o gênero ficou conhecido popularmente como gibi, que era o título de uma famosa revista da década de 1940.

A discussão sobre o que pode ou não ser considerado quadrinhos não é menos problemática. Em geral, existem duas formas de defini-los. A primeira é pela combinação de palavra e imagem. No entanto, essa definição traz problemas porque não seria suficiente para caracterizar essa mídia por si só, pois essa qualidade estaria presente em outras mídias híbridas. E, além disso, nessa definição, as sequências de quadrinhos sem palavras (por exemplo, as famosas sequências de três quadros verticais na última página das revistas da Turma da Mônica) não poderiam ser consideradas quadrinhos. A segunda maneira pela qual os quadrinhos podem ser definidos é pela disposição de imagens em uma sequência. Com base nisso, Will Eisner cunhou o termo "arte sequencial". Nessa definição, os quadrinhos consistem em, pelo menos, duas imagens sequenciais. Nesse caso, portanto, as composições de um quadro só não seriam consideradas quadrinhos. Além disso, apesar de o termo de Eisner conferir à mídia um status de arte, pode também erroneamente nos levar a considerar, por exemplo, os hieróglifos egípcios e a Coluna de Trajano como quadrinhos.

Em relação ao conteúdo, os quadrinhos podem designar um termo guarda-chuva para vários gêneros. Assim, é importante frisar que não se trata de um gênero da literatura, mas uma mídia por si só, portanto, com seus próprios gêneros e categorias. Podemos identificar os seguintes formatos de quadrinhos hoje em dia: revistas em quadrinhos, tirinhas, revistas de mangá, álbuns europeus, webcomics, fanzines, minicomics, produções de editoras independentes, etc.

Durante o século 19, eram destinados especialmente a adultos e publicados em formato de livro. Mas, assim que se tornaram fenômeno de massa, caíram nas graças do público infantil. Por vários anos, a distribuição nos EUA limitou-se aos títulos de 
super-heróis e os estudos sobre quadrinhos eram de educadores que, inspirados pelo livro Seduction of the Innocent, do psiquiatra Fredric Wertham (1954), acreditavam que o aumento da delinquência juvenil era consequência da influência negativa dos quadrinhos. Na Europa, em oposição aos EUA, autores como Hergé, Hugo Pratt e Guido Crepax tiveram um papel fundamental na manutenção dos quadrinhos em posição de prestígio entre leitores adultos no século 20.

No Brasil, as primeiras HQs eram as de humor, inicialmente inspiradas pelas histórias norte-americanas e europeias. A famosa revista $O$ Tico-Tico publicou versões abrasileiradas de personagens de humor estrangeiros desde o início do século 20, mas também abriu espaço para personagens originalmente brasileiros como Reco-Reco, Bolão e Azeitona. De qualquer forma, havia, no mercado, naquele tempo, quase que só HQs infantis e muitas delas eram reedições de sucessos norteamericanos. Basta dizer que "O Pato Donald, gibi da família Disney, foi a revista que fundou a editora Abril em 1950 e dominou longamente sua linha editorial" (Patati e Braga, 2006: 183). A ele uniram-se títulos como Luluzinha e Dennis, $O$ Pimentinha. HQs de aventura, a partir da década de 1930, e de adaptações de romances e de terror, a partir de 1950, também obtiveram sua fatia no mercado editorial brasileiro e ajudaram a consolidar a EBAL, a Rio Gráfica Editora (futura Editora Globo) e a Editora Outubro. No entanto, as denúncias do Dr. Wertham e o conservadorismo do período militar tiveram impacto no mercado editorial, especialmente entre as décadas de 1940 e 1960: enquanto as histórias de terror foram particularmente afetadas, os quadrinhos e charges de humor de grande senso crítico - como os dos artistas do semanário O Pasquim floresceram. Ainda assim, nesse período, o grande interesse do leitor brasileiro por narrativas de super-heróis fez com que vários superpoderosos nacionais surgissem e várias revistas de personagens americanos da Marvel e da DC Comics fossem publicadas no Brasil pouco depois de serem lançadas nos EUA. A partir de então, e pelas três décadas seguintes, 
pode-se dizer que o mercado editorial no país ficou dividido entre o quadrinho de super-heróis e o infantil. Dentre este público mais jovem, Pererê, de Ziraldo, e A turma da Mônica, de Mauricio de Sousa, alcançaram notoriedade a partir dos anos 1960. Este último foi menos afetado pela administração militar e alcançou grande sucesso a partir da década de 1970.

Mauricio de Sousa é considerado pela crítica especializada como o desenhista/cartunista brasileiro mais bem-sucedido atualmente (Moya, 1996). A "turma da Mônica" deixou de ser apenas um grupo de personagens para integrar o imaginário infantil nacional. $O$ artista conseguiu sucesso não só pelas suas histórias, mas também porseu senso mercadológico, ao promover suas obras por meio de adaptações para o cinema, televisão e video-games e até para os parques temáticos. A promoção engloba ainda uma série de produtos com a marca das personagens - material escolar, brinquedos, roupas e produtos alimentícios - que têm sido licenciados para 0 comércio.

Um dos projetos mais interessantes desse artista está na exposição História em quadrões, que se constitui de quadros realizados por reproduções de grandes obras primas, cujos personagens são substituídos por integrantes da "turma da Mônica" ou, como se afirmou no site oficial da exibição, as obras "retratam os personagens de Mauricio de Sousa interpretando os maiores gênios da pintura mundial". Mauricio dedicou-se a essa produção dos quadros e esculturas a partir de 1989. A proposta é estimular crianças e jovens a visitarem os museus para aprender sobre os grandes mestres das artes e, ao mesmo tempo, divertir-se. Assim, Mônica, Cebolinha, Chico Bento, Cascão e Magali, ao lado de outros tantos personagens do desenhista, fazem poses famosas numa alusão a importantes criações da história das artes plásticas. 

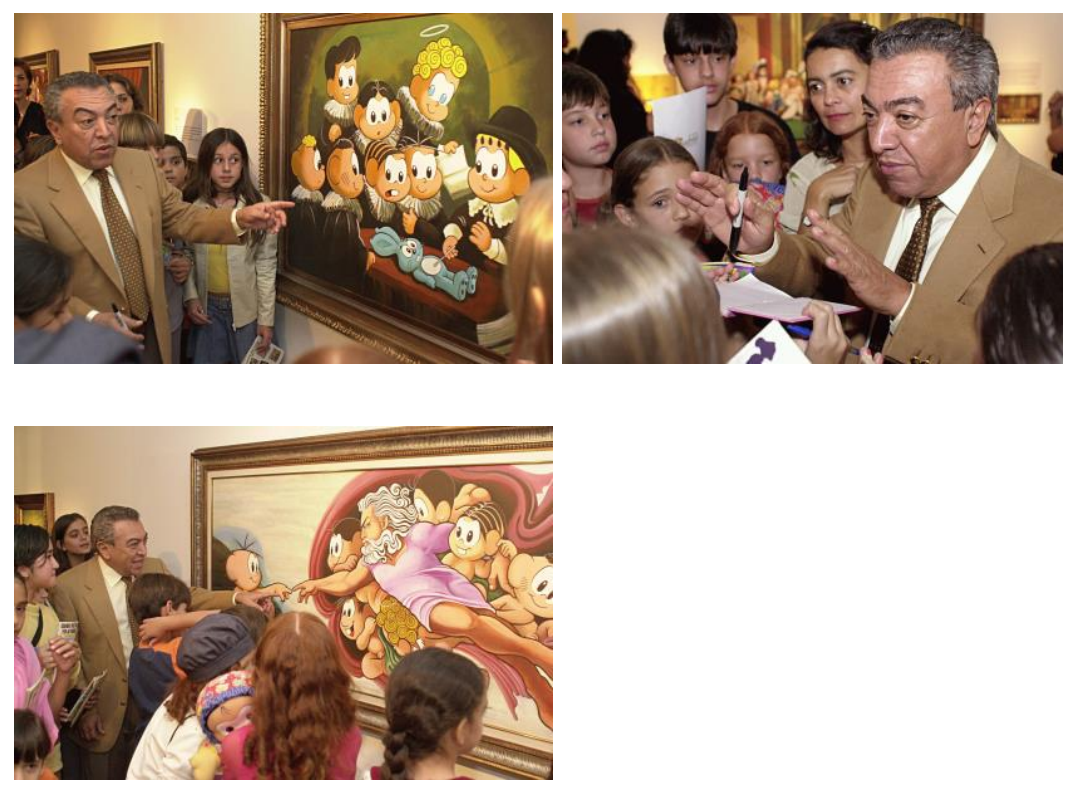

Fig. 1: Mauricio de Sousa em sua exposição, cercado de crianças.

Fotos: J. Freitas - $\mathrm{ABr}$. Disponíveis em http://memoria.ebc.com.br/agenciabrasil/galeria/2003-07-31/31-dejulho-de-2003.

Este artigo tem o objetivo de descrever aspectos das relações de duas obras constantes das mostras Histórias em quadrões 1 e 2 com a história do Brasil e com as que Ihes deram origem. Pretendo examinar e analisar como se estabeleceu a relação entre as telas originais e suas "traduções", mas também os efeitos de sentido no público infantil e juvenil para o qual as releituras de Mauricio de Sousa se destinam, ou seja, levar os jovens a "se aproximar dos grandes mestres da pintura, conhecendo suas vidas e obras e tendo também momentos lúdicos com [nossa] releitura" (História em quadrões) e, ao mesmo tempo, levá-los a se interessar por aspectos da cultura e história do Brasil. Entre as obras dos pintores famosos que foram apropriadas por Mauricio de Sousa, selecionei duas que têm ligação direta com a História do Brasil: $A$ dança dos Tapuias, de Albert Eckhout, e O lavrador de café, de Cândido Portinari. Essas obras foram criadas em tempos bem diferentes, constituindo-se assim não somente como marcas da história e da ideologia, mas também da estética (Arbex, 2000).

\section{A dança dos Tapuias, de Albert Eckhout}


Albert Eckhout foi pintor, desenhista, artista plástico e botânico holandês, autor de pinturas do Brasil que envolviam a população, os indígenas e paisagens da região Nordeste do nosso país. Os retratos de Eckhout impressionam por seu detalhismo e pelos traços realísticos, quase mesmo fotográficos. Não se pode esquecer porém que são representações alegóricas da riqueza brasileira e dos povos sob domínio da Companhia das Indias Ocidentais. As pinturas foram feitas para a admiração de Nassau no Palácio Friburgo, no Recife, e depois enviadas para o rei Frederick III, da Dinamarca. Não se tratava de um conjunto de imagens concebidas para admiração de um grande público.

Dentre todas as suas obras etnográficas aquela que causa mais espanto, ainda hoje, é $A$ dança dos Tapuias (ou Dança Tarairiu). O tamanho natural das personagens retratadas nos faz pensar que estão prestes a saltar da tela, consequência do movimento de seus corpos, capturado pela pintura como se fosse um instantâneo. Oito jovens índios musculosos aparecem dançando sob o olhar de duas índias aparentemente grávidas. O jovem mais próximo das mulheres encara o espectador como se o convidasse a tomar parte na dança, segurando um tacape ou um conjunto de flechas e seu arco (Oliveira, 2005).

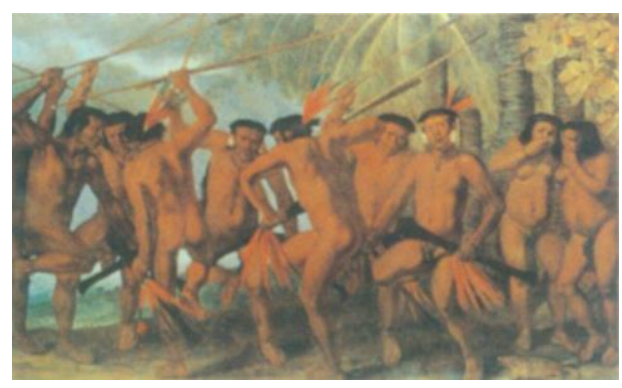

Fig. 2: A dança dos Tapuias, de Albert Eckhout, no National Museum of Denmark, Copenhagen

Usualmente interpretada como uma representação do mundo tropical antes da intervenção dos conquistadores, ou mesmo como uma representação dos índios Tapuias, aliados ocasionais dos holandeses em sua empreitada no Nordeste brasileiro, esta pintura traz, contudo, um pequeno detalhe que 
a torna extremamente significativa. Segundo Oliveira, os quatro coqueiros cujos troncos delimitam o palco são palmáceos originários das ilhas do Pacífico e da costa africana do Oceano Índico, trazidos ao Brasil pelos portugueses e que, portanto, não podiam figurar numa representação anterior à conquista. Sua presença ao fundo é um claro sinal da presença europeia nas terras em que viviam aqueles indígenas.

Eckhout não pretendia chocar os observadores de suas pinturas, especialmente os da dança dos Tapuias, pois elas foram pintadas para decorar as paredes do principal salão do Palácio Friburgo e, depois do retorno de Nassau à Europa, não deveriam perder essa função. As pinturas etnográficas são associadas às naturezas-mortas, pois junto com elas representavam a riqueza brasileira sob o domínio de Nassau e, consequentemente, seu triunfo como governante. Esses detalhes permitem pensá-las como alegorias do mundo holandês no Brasil e, como alegorias, esses retratos são também discurso: um discurso de dominação e tentativa de tradução dos trópicos através de parâmetros estéticos europeus.

A obra de Eckhout é significativa não só por se tratar das primeiras representações do Novo Mundo feitas in loco por um artista profissional. Representa, também,

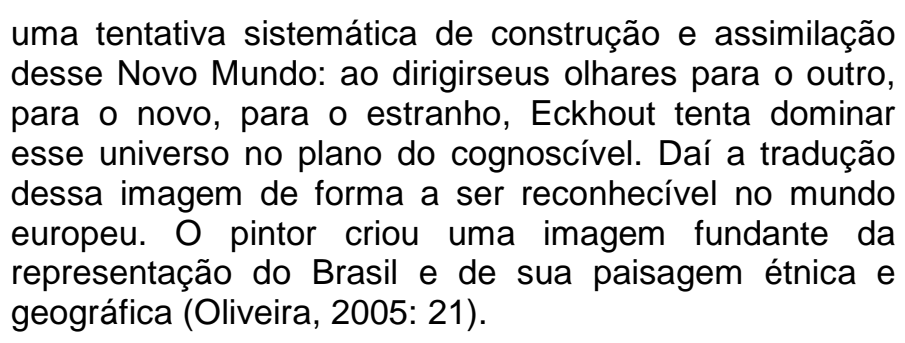

Em síntese, é possível afirmar que o objetivo dessa imagem era registrar a riqueza das terras sob domínio holandês na América portuguesa. Portanto, a cena criada a partir de motivações político-econômicas e, ao contrário do que se afirmou no imaginário ocidental moderno, não se constitui em "documento" do Brasil como uma terra sem males que 
esperava os viajantes para dar-lhes prazer, deleite e riqueza: é, na verdade, uma expressão alegórica barroca, pois mostra um mundo exótico produzido como "registro" teatralizado do real.

Pode-se considerar o quadro de Eckhout uma ilustração, que pode ter várias funções: mais do que simplesmente ornar ou elucidar um texto que não existe, pode enfatizar sua própria configuração e chamar a atenção para seu suporte ou para a linguagem visual. Segundo Hillis Miller, ilustração significa trazer "à luz, como uma lâmpada ilumina uma caverna, ou um manuscrito medieval é iluminado" (Miller, 1998: 61, minha tradução). De acordo com Benton e Butcher, a ilustração é o reverso da écfrase: em vez de o poema falar pela pintura silenciosa, as pinturas que ilustram leem silenciosamente o texto ao qual se referem e permanecem disponíveis para complementá-lo. No caso da pintura de Eckhout, é como trazer à tona algo que está no mundo real, e não o que está no texto, como ocorre com as ilustrações de romances. A pintura de Eckhout, ao contrário das ilustrações de romances, acabou por gerar um texto, mesmo que imaginário, na mente dos europeus. Estamos tratando de uma pintura que foi realizada com a função de documentar. Seria ela realmente uma ilustração? No conceito proposto por Irina Rajewsky, talvez se trate de uma referência intermidiática: uma pintura "como se" fosse fotografia.

\section{O lavrador de café, de Cândido Portinari}

Cândido Portinari nasceu em 1903 no interior de São Paulo e envolveu-se muito cedo com as artes. Aos 15 anos foi para o Rio de Janeiro onde estudou no Liceu de Artes e Ofícios e na Escola Nacional de Belas Artes. Dedicou-se intensamente à pintura, retratando na tela o povo brasileiro e buscou inspiração nas lembranças de sua terra natal. Embora sua formação inicial tenha sido bastante tradicional, Portinari sofreu influências das vanguardas europeias - o Expressionismo, o Cubismo e o Surrealismo - que foram determinantes para 0 seu envolvimento com as tendências modernas. A viagem à 
Europa, resultado de um prêmio conquistado em 1928, o levou até Paris, onde se instalou até 1930. Aí estudou e pesquisou arte e descobriu a pintura moderna. Casou-se com Maria Martinelli, com quem viveu até o fim de sua vida, quando morreu, em 1962, intoxicado pelas tintas que utilizava.

Portinari fez obras de arte em estruturas importantes de grandes dimensões, como o Monumento Rodoviário e o edifício do Ministério da Educação e Saúde, trabalhos que representam um marco na evolução de sua arte, que afirmou a opção pela temática social, fio condutor de toda a sua obra a partir daí. Seu trabalho denunciou as desigualdades sociais no Brasil e foi reconhecido internacionalmente, sempre caracterizado pelo volume dos corpos humanos e pés enormes, que relacionavam as figuras com a terra. Realizou painéis de grande importância histórica, entre eles $A$ chegada da família real à Bahia, os painéis Guerra e Paz, o São Francisco de Assis, na Igreja da Pampulha e vários murais gigantescos. Deixou grande quantidade de obras que retratam, de maneira expressionista, a realidade da população rural, notadamente os retirantes do Nordeste.

A tela de Portinari escolhida para este trabalho é O lavrador de café, que retrata um trabalhador negro em uma fazenda de café do início do século 20. Está entre as obras mais conhecidas do artista e é importante representação do interesse do pintor pela temática nacional.

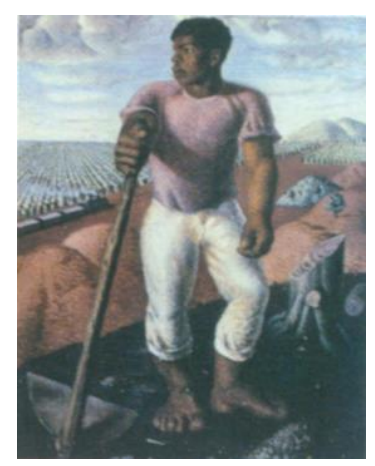

Fig. 3: O lavrador de café, 1934. Pintura a óleo/tela. Museu de Artes de São Paulo. 
No quadro, Portinari se volta para a questão da relação homem versus trabalho, ressaltando a figura do lavrador e seu instrumento de trabalho, a enxada, tendo ao fundo a plantação do café. Há um trem num movimento horizontal, separando a terra plantada da não plantada.

O modelo aparece bem mais musculoso que o normal. A figura deformada, com pés e mãos enormes, é o que aproxima a obra de Portinari do Expressionismo. Aumentar o tamanho do corpo de seus personagens era 0 jeito que o artista usava para mostrar a importância do trabalhador brasileiro. Essa deformação expressiva, notadamente a dos pés e das mãos de grandes figuras dramáticas e comoventes, pode ser considerada uma das características marcantes do pintor. Em primeiro plano, centralizada, aparece a figura do lavrador com os detalhes dos pés e das mãos disformes expressos de maneira exagerada. Pode-se mesmo comparar o tamanho desses membros com o tamanho da cabeça. Como esses, destaca-se também a enxada em sua mão direita, com a base enorme. As calças brancas contrastam com o chão escuro. Sobra pouco espaço acima e abaixo da figura. O pintor sugere a atuação do trabalhador rural na lavoura. Há uma árvore decepada, à direita, que pode ter a conotação de desmatamento e mudança da paisagem ocasionada pela cultura. Em segundo plano, aparecem os montes dos grãos já colhidos, com a iluminação ressaltando seus picos, na cor amarelada. Entre eles, estão presentes algumas árvores. Ao fundo temos figuras de cafeeiros, tanto na superfície plana como nos morros. Percebe-se que parte da plantação vai em direção ao espaço reservado para seleção e ensacamento. $O$ olhar do lavrador é expressivo e nele predomina a preocupação. Outro elemento presente no quadro, entre os pés de café e os montes de grãos, é o trem, o meio de transporte utilizado para enviar a produção cafeeira até o porto de Santos. Essa figura nos permite refletir sobre a História, pois como registra Lima "o café e a ferrovia sempre andaram juntos" (Lima, 2006). 
Quando esses detalhes que compõem o quadro são observados, começamos a entender 0 efeito dafigura do lavrador que, de imediato, se destaca na paisagem. A cena que é colocada numa colina da qual se vê uma extensa e longínqua paisagem com uma faixa de céu ao fundo destaca a parte superior do lavrador fazendo com que agrande plantação que se estende para além da montanha se apresente relativamente pequena em contraste com o tamanho do homem.

Como mencionado acima, O lavrador de café faz menção à temática social das mais recorrentes em Portinari que, só sobre esse tema, realizou cerca de 50 obras, tendo recebido, em 1935, a $2^{\text {a }}$ Menção Honrosa do Carnegie Institute, em Pittsburgh, nos EUA pela tela "Café", hoje pertencente ao Museu Nacional de Belas Artes do Rio de Janeiro. É uma das telas mais famosas de Cândido Portinari (1903-1962), cuja data é confusa. Para o MASP, ela teria sido elaborada em 1939, mas para o Projeto Portinari (http://www.portinari.org.br/), a obra data de 1934.

Os quadros discutidos acima representam dois olhares diferentes sobre o Brasil. O primeiro, de um estrangeiro, reflete a atitude que os conquistadores tinham a respeito de nossa terra - uma terra exótica e cheia de riquezas. O segundo, de um brasileiro culto que, tendo sido influenciado pelas escolas de arte estrangeiras, ainda assim foi capaz de enxergar - e denunciar - os problemas sociais de seu próprio país.

\section{O Brasil colonial e o Brasil moderno na mão de Mauricio de}

\section{Sousa}

Na primeira transposição realizada por Mauricio de Sousa - a pintura Dança do Papa-Capim -, os personagens da turma da Mônica aparecem fantasiados de índios, mas sua distribuição pelo quadro guarda a mesma proporção e disposição da pintura de Eckhout. 


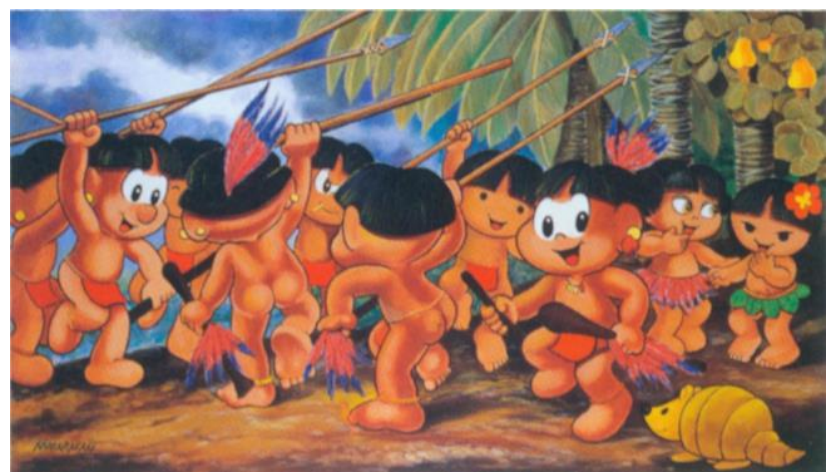

Fig. 4: Dança do Papa-Capim, 1991. Disponível em História em quadrões, 2002: 6.

Entretanto, para os leitores brasileiros, esta tela mais parece retratar um baile de carnaval. Talvez sirva, como mencionado pelo próprio artista, para despertar a curiosidade dos jovens para as criações artísticas realizadas no século 17 por artistas que procuraram retratar o Brasil para os europeus. Não se pode classificar este quadro como uma transposição intermidiática, uma vez que se trata de uma paródia na mesma mídia: a pintura. Podemos, entretanto, considerá-la um pastiche, pois "trata-se de uma prática de imitação que se distingue da subversão paródica por seu objetivo lúdico, não militante" (Charaudeau, 2004: 371).

A segunda transposição retrata o personagem Chico Bento, um típico caipira brasileiro, que anda descalço, usa chapéu de palha e adora pescar com o pai. Mora com os pais em um sítio nas cercanias da fictícia Vila Abobrinha, no interior de São Paulo, e tem uma avó contadora de "causos" e de histórias folclóricas, envolvendo lendas, tais como a da Mula semcabeça, do Saci, do Lobisomem, do Curupira, dentre outras. Acorda antes do nascer do sol para ajudar o pai na roça, vive tentando roubar goiabas do vizinho, brinca com os demais da turma e ainda namora a Rosinha. É um dos personagens mais populares e queridos É acomodado, eventualmente preguiçoso e um tanto mentiroso, mas principalmente aventureiro. Apesar de suas travessuras, Chico é um menino bondoso, generoso, ama a natureza e os animais, sejam eles selvagens ou do sítio. Enfim, é um representante do povo interiorano brasileiro. 


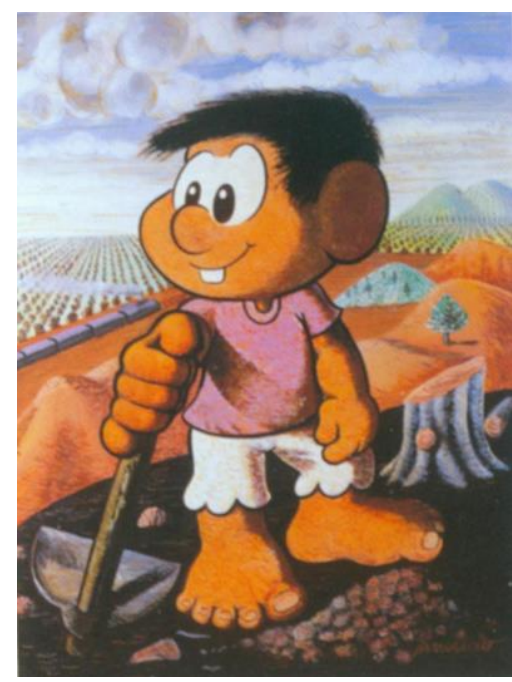

Fig. 5: Chico lavrador de café, 1989. Disponível em História em quadrões, 2002: 30.

No quadro paródico, Chico Bento, o personagem, descansa um pouquinho antes de voltar a ajudar o pai na lavoura. Como se vê, não há intenção de parodiar ou destruir o original, apenas de homenageá-lo; sendo assim, pode-se classificar esse "quadrão" também como pastiche, distinto da paródia, de caráter eminentemente subversivo, contestatório e oposicionista.

\section{Notas finais}

A análise crítica das relações intertextuais nos quadrões nos leva a adotar a noção de intericonicidade proposta por Arbex. A autora atenta para o caráter intertextual da produção artística, evidenciando "obras que se constroem como um mosaico de citações" e sugere o uso do neologismo intericonicidade, definido "nos mesmos termos que o conceito de intertextualidade, ou seja, como processo de produtividade de uma imagem que se constrói como absorção ou transformação de outras imagens" (Arbex, 2000: 3). No caso dos quadrões, os textos-fonte, isto é, os quadros originais em que Mauricio de Sousa se baseia (ou melhor, as reproduções reduzidas das telas) estão colocados lado a lado com sua "releitura". Dessa forma, a intericonicidade entre cada par de obras é explícita. Esse tipo de referência a trabalhos artísticos do passado não 
constitui fato isolado ou incomum. É característica da arte pós-moderna, na qual os "quadrões" de Mauricio de Sousa podem se enquadrar.

\section{Referências}

Arbex, M. (2000). Intertextualidade e intericonicidade. In: Oliveira, L. C. V. \& Arbex, M. (Org.), I Colóquio de Semiótica da UFMG. Belo Horizonte: FALE, 6. Disponível em

http://www.letras.ufmg.br/napg/LIVROCOLOQSEM7.doc.

Benton, M.; Butcher, S. (1998). Painting Shakespeare. Journal of Aesthetic Education, 32(3), 53-66, Autumn.

Charaudeau, P.; Maingueneau, D. (2004). Dicionário de análise do discurso. Trad. Fabiana Komesu. São Paulo: Contexto.

Feijó, M. (2003). Quadrinhos em ação. São Paulo: Moderna.

História em Quadrões - As pinturas de Maurício de Sousa. (2009). Disponível em http://arteimitaavida.blogspot.com.br/2009/01/histriaem-quadres-as-pinturas-de.html.

História em quadrões: pinturas de Mauricio de Sousa. (2002). São Paulo: Editora Globo; Mauricio de Sousa Editora.

lannone, L. R.; lannone, R. A. (1995). O mundo das histórias em quadrinhos. 3 ed. São Paulo: Moderna.

Koch, I. G. V. (2004). Introdução à linguística textual. São Paulo: Martins Fontes.

Lima, R. P. T. (2006). Amparo: flor da montanha. São Paulo: Nova América.

Mazon, P. (1998). Infelicities: Representation of the Exotic. Baltimore: The John Hopkins University Press.

Miller, J. H. (1992). Illustration. London: Reaktion Books.

Moya, A. (1996). História da história em quadrinhos. São Paulo: Brasiliense.

Mozdzenski, L.; Vaz, A.; Silva, M. C. H. (2008). Da obra-prima ao pastiche: multimodalidade e intericonicidade nos "Quadrões" de Mauricio de Sousa. 1. ed. Anais Eletrônicos. Recife: Universidade Federal de Pernambuco. Disponível em 
http://www.ufpe.br/nehte/simposio2008/anais/Leonardo-Mozdzenski-

e-Ana-Vaz.pdf.

Oliveira, C. M. S. (2005). O Brasil seiscentista nas pinturas de Albert Eckhout e FransJanszoon Post: Documento ou invenção do Novo Mundo? Disponível em

http://cvc.instituto-

camoes.pt/eaar/coloquio/comunicacoes/carla_mary_oliveira.pdf.

Patati, C.; Braga, F. (2006). Almanaque dos quadrinhos: 100 anos de uma mídia popular. Rio de Janeiro: Ediouro.

Projeto Portinari. Disponível em http://www.portinari.org.br/.

Rajewsky, I. (2012). Intermidialidade, intertextualidade e "remediação": uma perspectiva literária sobre a intermidialidade. In: Diniz, T. F. N. (Org.) Intermidialidade e estudos interartes: desafios da arte contemporânea. Belo Horizonte: Editora UFMG. 